Februray 2018

"Is there complementarity between labels and brands? Evidence from small French co-operatives"

\author{
M'hand Fares, Saqlain Raza and Alban Thomas
}




\title{
Is there complementarity between labels and brands? Evidence from Small French co-operatives
}

\author{
M’hand Fares*, Saqlain Raza, Alban Thomas ${ }^{\ddagger}$
}

Revised version: January 2015

\begin{abstract}
Many quality signals, both private and public, have been used to foster the development of food quality in the agro-food markets, mainly brands and common labels. Previous research has typically focused on either brand or common label efficiency independently, while in many instances both signals coexist. Agricultural products pairing brand names and certified labels, such as indications of origin, are indeed very common (e.g. Roquefort cheese, Scottish whiskeys and most of the French wines). The objective of our paper is to take into account this coexistence by empirically analyzing the complementarity and/or substitutability that may exist between labels and brands. To do so, we estimate an original multinomial probit model of complementarity that we test on a database of the quality signaling strategies from 993 small French co-operatives. Our main result shows that there is a clear interaction effect between brand and label signal strategies, but more as a substitution effect than as a complementary one.
\end{abstract}

Keywords: complementarity; quality signals; multinomial probit.

JEL Classification: C25, L15, Q12, Q13.

${ }^{*}$ Corresponding author: INRA, UMR 1248 (AGIR), Chemin Borde Rouge, BP 52627 F 31326 Castanet Tolosan cedex

${ }^{\dagger}$ UMR 1248 (AGIR), Chemin Borde Rouge, BP 52627 F 31326 Castanet Tolosan cedex

¥Toulouse School of Economics (LERNA, INRA), 21 allée de Brienne, 31000 Toulouse 


\section{Introduction}

Consumers demand for quality food has been increasingly drawing attention throughout the world, particularly in industrialized countries (Braham, 2003; Vanhonacker et al., 2010; Hu et al., 2011). Many quality signals can be used, both private (brand) and common (label), to foster the development of quality food in the market (Crespi and Marette, 2003; Lence et al., 2007). Previous research has typically focused on either brand or common label efficiency independently, while in many instances both signals coexist. Agricultural products pairing brand names and certified labels, such as indications of origin, are indeed very common (e.g. Roquefort cheese, Scottish whiskeys and most of the French wines) and the globalization of the agro-food industry seems to foster its development (Yue et al., 2006; Boizot-Szantai et al., 2005).

Our paper offers the first attempt to empirically test for this coexistence by estimating the complementary effect that may exist between labels and brands. First, we develop empirical models to test for complementarity between both signals. Since Arora (1996), it is usually considered that complementary between different practices can be estimated using a reduced-form (bivariate probit). However, unobserved heterogeneity may first bias the estimates. To overcome this problem, we use exclusion restriction and indirect test of complementarity by implementing a multinomial logit model. Unobserved heterogeneity may also make incoherent the discrete response model of the reduced-form approach (Miravette and Pernias, 2010) ${ }^{1}$. To avoid this incoherence problem, we estimate a multinomial probit model to recover the structural parameters by separating complementarity from unobserved heterogeneity.

Second, to estimate the reduced and structural form models of complementarity between quality signals we use a sample of 993 small French co-operatives. The co-operatives may choose between four strategies of quality signaling: no signal, label only, brand only, and a mixed signal (label and brand). The question we address is then if the mixed signal is due to complementarity, i.e. the joint adoption of two signals (label and brand) is due to the net gain generated by the combination of signals, or to unobserved heterogeneity between co-operatives.

Our estimations show two main results. First, the estimation of the structural model using a multinomial probit approach exhibits a clear effect: there is a robust interaction between label and brand variables, but the interaction is negative. This implies that both signals are more substitutable than complementary. Second, using a reduced-form approach (bivariate probit) generates at least biased estimates due to unobserved heterogeneity. Indeed, we get a result of complementarity (the correlation parameter between errors is positive) while the indirect test of complementarity run on the multinomial logit estimation provides no clear evidence of complementarity.

The remaining sections are organized as follows. In section 2 , we provide elements of context on small French co-operatives and their quality signaling strategies. In section 3, we present and

\footnotetext{
${ }^{1}$ The discrete response model is incoherent because it is not possible to associate any realization of the vector of error terms with a unique combination of strategies. To avoid such incoherence problem in a bivariate probit, any complementarity among strategies should be excluded so that the estimated correlation coefficient is only evidence of correlation among unobserved returns of each strategy.
} 
discuss the complementary effect and the empirical models to test for this effect. Section 4 presents the database and the different variables used in the test. Section 5 discusses and comments the results of the empirical models on complementarity or substitutability between labels and brands. Section 6 gives some concluding remarks.

\section{Background on small French co-operatives}

Despite the general trend of growth in the size of agricultural cooperatives and agro-industrial firms, small co-operatives continue to play a significant role in farming activities in France. Indeed, even if the 1,500 small co-operatives represent less than $1 \%$ of the agri-food products, they make a total sales turnover of 3.6 billion euros, and are the first intermediary of over 100, 000 small farmers. Small co-operatives are then closely engaged in the farmers production and marketing strategic choices. Co-operatives are heterogenous in their organizational structure, the type of products they sold and their markets (2.1), as well as in their quality signaling strategies (2.2).

\subsection{Organizational structure, products and markets}

Recall that an agricultural co-operative is a legal category of society, different from civil and commercial companies since it is a non-profit organization. The main feature of a small cooperative is its small size. That is, a small co-operative is defined as a co-operative with less than 10 employees. On average, the small co-operatives in France have less than four-full-time equivalent employees (see table 1 for some statistics). However, we observe a large variability among the co-operatives since some of them have no employees, while others are at the threshold of 10 employees. Due to this scarce labor factor, farmers - as members of the co-operative - carry out a large number of jobs, particularly in seasonal periods of intense activity. There is also a large variability in the number of members (from one to ten) as well as in the sales turnover. Indeed, if $50 \%$ of of the small cooperative have a total sales turnover less than 1.2 millions $€, 25 \%$ of the processing co-operatives realize more than 2.5 millions $€$ while $25 \%$ of wholesaling co-operatives have a turnover higher than 4.3 millions $€$. Moreover, $10 \%$ of the co-operatives realize $50 \%$ of the sales turnover in the wholesaling activity. That is, the co-operatives having the largest sales turnover are wholesalers ${ }^{2}$.

To perform their intermediary function, co-operatives as non-profit organizations face also low equity levels and high marketing costs (Hansmann, 1996; Cook and Iliopoulos, 2000). To circumvent this problem, small co-operatives may choose different governance mechanisms. First, to benefit

\footnotetext{
${ }^{2}$ This can be partly explained by the fact that less than ten number of employees is not the only constraint that define a small cooperative. There is also a threshold of total sales under which a co-operative is considered as "small". This threshold is not the same for the processors and for the wholesalers: 5 millions $€$ for processors and 38 millions $\in$ for wholesalers.
} 
from economies of scale and having access to some heavy equipments (building, logistic facilities, ...), co-operatives may be an associate or a member of an union of cooperatives (Filippi et al., 2006). 40\% of small co-operatives are members or associates of an union of co-operatives. Second, to reduce its marketing costs by selling directly its products a small co-operative can take the control of a subsidiary firm that has a direct access to market (Hendriksen and Bijman, 2002). This strategy is developed by $15 \%$ of the co-operatives, notably those with the highest sales turnover.

Small co-operatives sell also different products and have access to different markets. First, if mainly process and/or sell beverage (48\%), particularly wine ( $85 \%$ of the beverages), and dairy products $(28 \%)$, there is a slight difference between wholesaling co-operatives (63\% of the whole sample) and processing co-operatives (37\% of the whole sample). Wholesalers are specialized in wine and dairy products (respectively, $60 \%$ and $25 \%$ of the whole sample), while processors have a more diversified portfolio of products, e.g. the share of the first three types of product sold is quite the same: milk, eggs and oil (25\%), grain and animal feed (20\%), fruit and vegetables (17\%).

Second, small co-operatives mainly sell local products in local and regional markets but some of them have access to export markets. Indeed, more than three-quarter have exclusively regional customers and $86 \%$ of them make more than $50 \%$ of their sales turnover in the same marketing channel (the first marketing channel is the co-operative network (30\%)). But small co-operatives do not sell only to local markets since $20 \%$ of the sales turnover are realized with other regions in France and $7 \%$ of the co-operatives export their products to other countries for $6 \%$ of the total sales. Exports are mainly oriented to the EU markets and, to a lesser extent, to markets outside of the EU borders. The exporting co-operatives are among the largest ones, with a median sales turnover double than the one of the cooperatives selling exclusively to the domestic market.

\section{- insert Table 1 -}

\subsection{Quality signals: public labels and private brands}

The livelihood of small French farmers depend on their access to markets, and more particularly to their access to "niche" markets where quality signals may generate some value (Braham, 2003; Aubert and Perrier-Cornet, 2010). To signal quality, the cooperative, as a marketing intermediary acting on behalf of its members, may use different quality signals: label, brand, or a mix signal where label and brand are jointly adopted. Note these three quality signals are managed, owned (brand) or co-owned (labels) by cooperatives and not by their members (farmers).

Labels are common signals of quality adopted by different cooperatives. In France and in other European countries, these labels refer to public labels regulated by the State and the European Commission. They can be Geographical Indications such as PDO or $\mathrm{PGI}^{3}(\mathrm{AOC}, \mathrm{IGP}, \ldots)$ and

\footnotetext{
${ }^{3}$ In the case of PGI it suffices that one stage of the production process is carried out in the defined area, while in the case of a PDO, all stages of production must take place in this area.
} 
cooperatives in the same geographical area are co-owner of the $\mathrm{GI}^{4}$. They make decisions regarding their products and a consortium is often created to enforce the standards imposed by the IG system. It act as a third party supervisor that includes verification of origin, quality, food safety and sometimes marketing functions. Public labels can also be used to signal other dimensions of the product than geographical indication, e.g. organoleptic quality of the product (Label Rouge) ${ }^{5}$ or the environmental-friendly production practices adopted by the farmer (organic farming, AB).

In contrast, brands are private quality signals since the cooperative has the exclusive ownership of the signal and ensure alone its management and bears all the costs. The brand is more often the name of a product, e.g. "Pates du Lauragais" (Lauragais Pasta) than the name of a store. If there is often a clear reference to a geographical indication in the brand name (e.g. Lauragais ${ }^{6}$ in "pates du Lauragais") since small cooperatives mainly market the local products of their members, brands are distinct from IGs because they are private and thus there is no public certification or regulation of the geographical indication ${ }^{7}$.

Our definition of labels and brands is very similar to the two ways of labelling geographical indications (see Sven and Caswell, 2008; Marette et al., 2008). The first way is the European model where geographical indication labelling is done through public labels (IGs). The second one is the United States model, where geographical indication labelling is done through trademark or brand name system.

In our sample, $71 \%$ of the small co-operatives adopt a quality signal. The different quality signals chosen by the co-operatives are distributed as follows: (i) $29 \%$ of small co-operatives use no quality signal; (ii) $48 \%$ of them use labels only; (iii) $5 \%$ use brands only; and (iv) $18 \%$ of the co-operatives use a mixed signal strategy by adopting both signals. Among the different public labels, IGs (AOC and PGI) are predominant ( $81 \%$ of the labels; see table 2 ). Those signals are especially developed for wine and cheese since $79 \%$ of dairy products and $64 \%$ of alcoholic beverages are sold with an IG. Other labels hold a significant position, particularly the organic farming (AB), even if this strategy of adopting more than one label is less frequent in our database ${ }^{8}$.

\footnotetext{
${ }^{4}$ In the US, certification mark laws protect individual products based upon their origin or region of production. A certification mark is defined as "Any word, name, [...] used or intended for use in commerce with the owner's permission by someone other than its owner, to certify regional or other geographical origin [...] performed by members of a union or other organization" (USPTO, 2003). As in the EU GIs system, any producer/ organization who meets the certification mark is entitled to use the mark. In contrast, there is no certification of the origin and no supervision system of quality (Marette et al., 2008).

${ }^{5}$ The Label Rouge certifies that processed and unprocessed food or non-food agricultural products have specific organoleptic or sensorial quality, which distinguish them from products and foodstuffs normally sold. This signal is very common for meat and poultry.

${ }^{6}$ Lauragais is a region in the south of Toulouse.

${ }^{7}$ The French brand system is very similar to the US trademark system defined as "any word, name, symbol, device [...] to identify and distinguish the goods of one seller from goods sold by others, and to indicate the source of goods. In short, a trademark is a brand name (USPTO, 2003)". An example of trademarks in the US, very similar to the brand "Pates du Lauragais", is the brand name "Cuties California Clementine" for Clementines citrus from farms in California owned by Sun Pacific Producers.

${ }^{8}$ Among the $65 \%$ of co-operatives adopting at least one label, only $15 \%$ have more than one label (see table 2 )
} 


\section{- insert Table 2 -}

Branding is much less common since it concerns less than a quarter of small co-operatives $(22 \%)$. Very few co-operatives choose to hold only a brand signal (5\% of the whole sample and $25 \%$ of those adopting brand) since brand is primarily associated with a label (18\% of the whole sample and $75 \%$ of the co-operatives that choose the brand signal). Co-operatives choosing a mix signal are mainly wine making processors $(75 \%)$ and are not very geographically anchored (35\% realize less than $50 \%$ of total sales in the same region). In average, they have a higher total sales turnover and are among the most exporting co-operatives (44\% that export inside EU borders and $12 \%$ outside EU borders).

For those co-operatives exporting outside European borders, the development of brands and mix signals in France is strategic, particularly in the wine industry (Yue et al., 2006; Boizot-Szantai et al., 2005). For example, since the protection of property rights in food products is not the same in Europe and in the US (public labels (IGs) vs certification marks), an exporting co-operative must have or create a trademark/ certification mark (depicting the place of origin for the product through a brand name). This can be done by choosing a brand only or by adding a brand to the public label (mix signal). But this implies a slight change since what is important in the mark system is the linkage between the owner and its product; the geographic link is secondary. Therefore, the european product sold in the US looses its IG status and becomes partly generic. Notice that this strategy of protecting only brand name and not the origin by itself is rational because product origin is less important to consumers in the US (Marette et al., 2008; Anders and Caswell, 2008).

\subsubsection{Related literature on food quality signaling}

Quality signaling is widespread for food and agricultural products, as these products are subject to market failures due to asymmetric information (Akerlof, 1970). In an asymmetric information context, the firm is supposed to know the good attributes that consumers can only determine through search or experience or that they cannot determine at all (Darby and Karni, 1973). This problem impacts negatively on the market: the quality of total supply drops and higher quality goods are driven out of the market due to adverse selection effect. In response to the unfair competition from firms who sell lower quality goods at the same price, the firm maintaining the quality of its goods can adopt a private brand to create the reputation of being a "high quality firm" (Klein and Leffler, 1981; Shapiro, 1983).

If a brand system can be an efficient mechanism for signaling quality, its cost can be prohibitive for small individual firms and/or small co-operatives in agriculture and food production. Small firms or co-operatives can then be a member of a "club" to achieve the critical mass required for label certification through a common public label. Allowing collusion may indeed improve general welfare by enabling these firms to cover the fixed costs of quality development and certification (Marette and Crespi, 2003; Lence et al., 2007; Mérel, 2009). In many European countries, this common 
labeling was mainly done with geographically based public labels, or geographical indications (GI) such as PGI (Protected Geographical Indications) and PDO (Protected Designation of Origin), where quality attributes are presumed to be linked to the specific geographic origin of the good produced. This is generally referred to as quality-origin nexus or terroir ${ }^{9}$.

There is some evidence that common public labeling, as an institutionalization of a collective reputation, enables to generate price premium for firms (Thiedig and Sylvander, 2000; Loureiro and McCluskey, 2000). For instance, Loureiro and McCluskey (2000) analyzed the consumer willingness to pay for GI public labels and show that when collective reputation is good, a GI is a powerful tool to promote quality and obtain a price premium ${ }^{10}$. However, GIs have also shortcomings since they may not necessarily prevent free riding in collective reputation. Winfree and McCluskey (2005) show that with positive collective reputation and no supervision system there is an incentive to firms to free ride, i.e. to extract rents by producing a lower quality level (Chambolle and Giraud-Héraud, 2005). Thus, as shown by Landon and Smith (1997, 1998), it can be efficient to use both collective and individual reputations to solve this problem by having recourse to a mixed signal (label and brand).

There is a burgeoning theoretical literature dealing with this issue of complementarity or concurrent use between public labels (GIs) and private brands (trademarks). Menapace and Moschini (2012), extending the model of Shapiro (1983) to reflect in a competitive market both collective (public GIs) and firm-specific (private trademarks) reputations, show that GIs and trademarks turn out to be complementary signals of quality. Indeed, if GIs reveal information regarding the origin of a product, they can also reduce costs of building reputation by constraining moral hazard behavior. Therefore, GI certification may improve welfare compared with a situation where only private trademarks would be available to firms. Costanigro et al. (2012), following Tirole (1996) and Winfree and McCluskey (2005), go one step further and analyze the conditions under which both public labels (common reputation) and private brands (private reputation) may coexist.

To our knowledge there is no empirical work testing for the coexistence between label and brand. Our paper is then the first that aims to: (i) develop an empirical model to test for complementarity/substitutability between quality signals (section 3); (ii) test for complementarity using a small French co-operative database on quality signaling (section 4 and section 5 ).

\footnotetext{
${ }^{9}$ Terroir, a French term for "taste of place", refers to a causal relationship between agronomic conditions, craftsmanship and a product distinct quality (Giovannucci et al., 2009).

${ }^{10}$ Bonnet and Simioni (2001) show in contrast that consumers do not place significant value on the PDO labeled French Camembert, and that brand appears to be more relevant in the consumer's evaluation of alternative Products. Gergaud and Ginzburgh (2008) find also no significant value on the PDO labeled Bordeaux wine.
} 


\section{Testing for complementarity}

\subsection{The theoretical approach}

In order to test for complementarity of labels and brands we apply an empirical strategy that is based on the theory of supermodularity. This theory of supermodularity was mathematically developed by Topkis (1978), and first introduced in industrial economics by Milgrom and Roberts (1990) to explain innovation adoption in firms.

In the context of supermodularity, two signals are complementary if: (i) adopting one signal does not preclude adopting the other; (ii) whenever it is possible to implement each signal separately, the sum of the profit to do just one or the other is not greater than the profit of doing both together. More formally, consider a market with $n$ small co-operatives deciding whether or not to adopt common labels $(l)$ and brands $(b)$. Each signal can be adopted or not by the co-operative $i=1, \ldots, n$. That is, $l=1$ if the co-operative adopts a common label, 0 otherwise; similarly $b=1$

if the co-operative adopts a brand, 0 otherwise. The payoff function $\pi_{i}(l, b)$ is supermodular and $l$ and $b$ are complements if

$$
\pi_{i}(1,1)-\pi_{i}(0,1) \geq \pi_{i}(1,0)-\pi_{i}(0,0)
$$

That is to say, adding a signal while the other signal is already adopted has a higher incremental effect on performance $\left(\pi_{i}\right)$ than choosing the signal in isolation.

\subsection{The empirical models}

Athey and Stern (1998) show that the problem of testing for complementarity can be tackled using two approaches. First, the direct approach involves using a production function to determine the effect of choosing particular combinations of innovation strategies on a firm's innovative performance (Belderbos et al., 2006; Cassiman and Veugelers, 2006; Mohnen and Röller, 2005). Using this approach allows for a direct test of the complementarity constraints, by testing multiple inequality constraints simultaneously (Mohnen and Röller, 2005).

The direct approach, however, requires a measure of the innovation performance, which is not always available. When we do not have such a measure, we must use an indirect approach: the adoption approach. This tests for a positive correlation between different innovation strategies conditional on a vector of exogenous variables $X$. More precisely, it involves examining firm simultaneous decisions in a bivariate model and analyzing cross-equation correlation in the error terms, conditional on firm characteristics (Arora and Gambardella, 1990).

Testing for correlation to infer complementarity derives from the theoretical approach on complementarity presented above. To show this, suppose that the previous payoff function $\pi_{i}($.$) depends$ also on a vector of exogenous variables $(X)$, and assume that $\pi_{i}(l, b, X)$ is supermodular in $(l, b)$. 
Then the optimal configuration of signals $S^{*}(l(X), b(X))$ is monotone non-decreasing in $X$ (Milgrom and Roberts, 1990). As shown by Arora (1996), this implies that if a pair of signals $(l, b)$ is complementary then the signals will be correlated when there is heterogeneity in $X$ across firms (cross-sectional study). A bivariate probit regresses the non-exclusive quality signals $l$ and $b$ on assumed exogenous variables $(X)$ but takes the correlation between them explicitly into account. This model can be written as follows:

$$
\begin{array}{ll}
l_{i}^{*}=\beta^{1} X_{i}+\varepsilon_{i}^{1}, & l_{i}\left\{\begin{array}{c}
=1 \text { if } l_{i}^{*}>0 \\
=0 \text { otherwise }
\end{array}\right. \\
b_{i}^{*}=\beta^{2} X_{i}+\varepsilon_{i}^{2}, & b_{i}\left\{\begin{array}{l}
=1 \text { if } b_{i}^{*}>0 \\
=0 \text { otherwise }
\end{array}\right.
\end{array}
$$

where $l_{i}^{*}$ and $b_{i}^{*}$ are latent variables. The errors are such that

$$
E\left(\varepsilon^{1}\right)=E\left(\varepsilon^{2}\right)=0 ; V\left(\varepsilon^{1}\right)=V\left(\varepsilon^{2}\right)=1 ; \operatorname{Cov}\left(\varepsilon^{1}, \varepsilon^{2}\right)=\rho
$$

The main intuition of the bivariate probit model is the following: in the presence of complementarity, a variable that affects only one of the signals directly, say $l$, appears as significant in both regressions, since complementarity induces an indirect effect from this variable on the adoption of $b$. That is, the indirect approach gives an indication of complementarity based on the assumption that the actual choice of the chosen signal maps the co-operative optimal decision.

The indirect approach encounters however two difficulties. First, unobserved heterogeneity between different co-operatives could bias the estimation results and lead to either accepting the hypothesis of complementarity while non-complementarity exists, or to rejecting the complementarity hypothesis when activities are in fact complementary. In order to account for this unobserved heterogeneity, it is recommended to use an exclusion restriction that directly impacts one of the signals, but not the other. Indeed, suppose that an increase in $X_{k}$ increases only activity $s^{1}$ directly. But because of complementarity between activities $s^{1}$ and $s^{2}, X_{k}$ will indirectly increases activity $s^{2}$. Therefore, $s^{2^{*}}$ will be non decreasing in $X_{k}$ in the presence of complementarity (Athey and Stern, 1996). That is, if there is complementarity between two different signals there will be a positive effect on the combined use of both signals (Cassiman and Veugelers, 2006). We implement this indirect test of complementarity, or "reduced-form test" (Athey and Stern, 1998), by estimating a multinomial logit model for the mutually exclusive signals: none, label only, brand only, both (mix signal).

The second difficulty is more severe since the estimation of a coherent bivariate probit model leads to exclude any complementary effect. Indeed, as shown by Arora (1996), the indirect approach supposes that the innovation strategies are continuous variables, whereas decisions on innovations are discrete in most common situations (Milgrom and Roberts, 1990). But the extension to the case of binary variables by using a bivariate probit (Cassiman and Veuglers, 2006) makes the discrete response model incoherent (Miravette and Pernias, 2010). That is, it is not possible to associate any realization of the vector of error terms with a unique combination of strategies. 
To avoid such incoherence problem in a bivariate probit, any complementarity among strategies should be excluded so that the estimated correlation coefficient is only evidence of correlation among unobserved returns of each strategy.

Using a multinomial probit solves this problem since it becomes possible to estimate separately a correlation coefficient in the error terms, to capture the unobserved returns, and a parameter of complementarity (Gentzkow, 2007; Fares, 2013). In a multinomial probit, the co-operative makes a choice $k$ on exclusive quality signals. The four exclusive choices are: $k=0$ when the co-operative neither adopts common labels nor brands $\left(l_{i}=0, b_{i}=0\right) ; k=1$ when the co-operative chooses a common label but does not adopt a brand signal $\left(l_{i}=1, b_{i}=0\right) ; k=2$ when it does not choose $l_{i}$ but chooses $b_{i}\left(l_{i}=0, b_{i}=1\right)$; and $k=3$ when it chooses both signals $\left(l_{i}=1, b_{i}=1\right)$. Then, the payoff function to be maximized can be written as follows

$$
\pi_{i}^{k}\left(l_{i}, b_{i}\right)=\left(\nu_{i}^{0}+\eta_{i}^{0}\right)+l_{i}\left(\nu_{i}^{1}+\eta_{i}^{1}\right)+b_{i}\left(\nu_{i}^{2}+\eta_{i}^{2}\right)+l_{i} b_{i} \theta
$$

The payoff has observable and unobservable components. The observable component associated with common label $\left(\nu_{i}^{1}\right)$ and brand $\left(\nu_{i}^{2}\right)$ are a function of user characteristics. That is, $\nu_{i}=$ $\beta^{k} z_{i}$ where $z_{i}$ is the vector of explanatory variables describing individual and alternative specific characteristics and $\beta^{k}$ are coefficients to be estimated. The random component $\eta^{k}$ of unobservable characteristics, related with decision $k$, has zero mean and covariance matrix $\sum=\sigma_{i}^{k}>0, \forall k$. If we normalize the payoff by taking $k=0$ as the reference, we get

$$
\left\{\begin{array}{c}
\widetilde{\pi}_{i}^{0}=0 \\
\tilde{\pi}_{i}^{1}=\widetilde{\nu}_{i}^{1}+\widetilde{\eta}_{i}^{1} \\
\widetilde{\pi}_{i}^{2}\left(l_{i}, b_{i}\right)=\widetilde{\nu}_{i}^{2}+\widetilde{\eta}_{i}^{2} \\
\widetilde{\pi}_{i}^{3}=\theta+\left[\widetilde{\nu}_{i}^{1}+\widetilde{\nu}_{i}^{2}\right]+\left[\widetilde{\eta}_{i}^{1}+\widetilde{\eta}_{i}^{2}\right]
\end{array}\right.
$$

with $\widetilde{\pi}_{i}^{k}=\pi_{i}^{k}-\pi_{i}^{0}, \widetilde{\nu}_{i}^{k}=\nu_{i}^{k}-\nu_{i}^{0}$ and $\widetilde{\eta}_{i}^{k}=\eta_{i}^{k}-\eta_{i}^{0}$. We know that there is complementarity between two signals when the profit of adopting quality signals jointly $(k=3)$ is greater than the value of adopting them separately $(k=1$ or $k=2)$. Using (1), we have

$$
\widetilde{\pi}_{i}^{3}+\widetilde{\pi}_{i}^{0}>\widetilde{\pi}_{i}^{1}+\widetilde{\pi}_{i}^{2}
$$

From the system (5), this can be rewritten

$$
\theta=\tilde{\pi}_{i}^{3}-\left[\tilde{\pi}_{i}^{1}+\tilde{\pi}_{i}^{2}\right]>0
$$

That is, there is complementarity (substitutability) when the constant term $\theta$ is positive (negative $)^{11}$.

\footnotetext{
${ }^{11}$ The identification of the multinomial probit model is however tenuous unless exclusion restrictions are present,
} 


\section{Data and variables}

Our data comes from a national survey of 1,500 small French agricultural co-operatives conducted in 2005 by the Ministry of Agriculture ${ }^{12}$. This periodical survey aims to study the economic conditions of small agricultural co-operatives processing and marketing excluded from the SCEES ${ }^{13}$ annual business survey. From the exhaustive sample of 1,500 surveyed co-operatives, 993 answered every question ${ }^{14}$.

\subsection{Test variables}

The dependent variables in our empirical models are the different quality signal strategies of the small co-operatives. The latter may choose (i) no quality signal (NSIG); (ii) label only (LABEL); (iii) brand only (BRAND); or (iv) a mixed signal by adopting both signals (LABRAND).

Different variables may explain the quality signaling strategy. The first driver is the size of the co-operative since a larger co-operative may adopt (costly) quality signals. The variable used to define the size of a small co-operative is its number of employees. We build a variable indicating the number of employees in the co-operative (EMP). Due to the scarce labor factor, farmers - as members of the co-operative - carry out a large number of jobs, particularly in seasonal periods of intense activity. Thus, we add a variable MEM indicating the total number of members. Another variable used as a proxy of the size is the turnover. The continuous variable TURN indicates the log of turnover (millions of euros) realized by the co-operative.

The second driver that may explain the quality signaling strategy is the governance of the cooperative (Cook and Sykuta, 2001). Union of co-operatives membership or association is indicated by the dummy variable, UNION. As a member of an union, the small co-operative may have less decision power on its own signaling strategy and thus follows the common labeling strategy of the union. In contrast, the small co-operative may increase its decision power by holding a subsidiary. We build a dummy variable SUBSID indicating when the co-operative has a subsidiary firm.

The third set of variables that may explain the choice of a quality signal is the market structure. First, small co-operatives have a local anchorage because of the location of their members. We

i.e. there are some alternative-specific attributes which should enter only the profit associated with one alternative and not the others (Keane, 1992). In the implementation of the multinomial probit, our estimations of $\beta_{i}^{k}, \theta$ and $\sum$ are obtained through exclusion restriction. Without exclusion restriction, high probability of choosing both signals $(k=3)$ may be because of high $\theta$ or large covariance between $\widetilde{\eta}_{i}^{1}$ and $\widetilde{\eta}_{i}^{2}$. Then, it is not possible to separate complementarity and unobserved heterogeneity.

${ }^{12}$ Enquête sur les petites coopératives agricoles et forestières, 2005.

${ }^{13}$ Service centrale des enquêtes et des études statistiques (Central office for statistical surveys and studies).

${ }^{14}$ To build the database, we used the full information from the survey. Note that we also tested for a selection bias between the two categories of cooperatives, those in the study and those omitted because they have not answered every question. We find no systematic differences between both categories. 
add a dummy variable (LT50INREG) which equals one when the co-operative makes less than $50 \%$ of its turnover in the region. Export market represents $3 \%$ of total sales, mainly for the EU markets, and $44 \%$ of total sales exported have recourse to brands and public labels. We build two continuous variables for the exporting co-operatives: $(i)$ the percentage of total sales from export within the EU (EXINEU); and (ii) the percentage of total sales from export outside of the EU (EXOUTEU).

We control for the different kind of channels, according to whether the co-operative sells its product to the co-operative marketing network (CN), supermarkets (SUPER), retailers (RET), wholesalers (WS), or hotels and restaurants (OTHER_HOT). 86\% of small co-operatives use only one marketing channel. We build a variable that equals one when the co-operative makes less than $50 \%$ of its turnover with the same marketing channel (LT50SM). And there is a large difference in the marketing channels depending on the quality signal chosen. For instance, while $16 \%$ of the co-operatives using a brand signal have recourse to supermarkets, only $4 \%$ of those having a label sell to supermarkets.

The type of activity and products sold can also explain the signaling strategy. To account for the different effect of the processing and the wholesaling activities, we create PC (processing cooperatives) and WSI (wholesaling co-operatives) dummies. To analyze more precisely the impact

of the different categories of product, we build five dummy variables representing the main types of product: (i) beverage, mainly wine (BEV); (ii) cereals (CER), (iii) fruit and vegetables (FVEG); (iv) meat (MEAT) and (v) milk, eggs and oil (MILKOIL).

- insert Table 3 -

\section{$5 \quad$ Results and interpretations}

We explain the quality signal strategies by estimating first a bivariate probit and a multinomial logit (4.1). Then, we provide a multinomial probit robust estimation of complementarity (4.2).

\subsection{The bivariate probit}

With the estimation of the bivariate probit model, we start with an investigation of the correlation between both quality signals (label and brand) conditional on size and governance characteristics of the co-operative as well as the market structure variables. Label and brand are defined as non-exclusive quality signals, i.e. it is possible that the co-operatives may use both. 
The results for the bivariate probit estimations are presented in table 3 . We estimate first a bivariate probit model without endogeneity correction (model 1), then we estimate different models to treat for endogeneity biais (models 2, 3, 4; see appendix for details). The first important finding is that there is a significant positive relationship between label and brand signals as indicated by the positive and significant correlation coefficient $\rho$. And this result is robust to endogeneity bias correction. This suggests that label and brand signals are likely to occur in combination and hence is a first indication of complementarity.

To explain this possible complementary effect between labels and brands, we need to analyze the different variables that have a significant effect on the adoption of label and brand signals. Concerning the size and governance variables, the small co-operatives that have a higher number of employees (EMP), turnover (Turn) and, are members or associate of a larger co-operative (Union), generally choose preferably a common label. In contrast, the co-operatives that have both higher employees and members (MEM) choose a brand strategy.

This may suggest a strong contrast between: (i) small co-operatives that have a "cooperative" strategy of growth by developing their relationships and organizational proximities with bigger cooperatives, and thus choose a common signal like a label; and (ii) co-operatives that have a "selfish" strategy of growth with more employees and members and develop their own quality signal, i.e. brand. The dummy variable PROC (processing activity) help to control for this heterogeneity between co-operatives ${ }^{15}$. We observe the same difference for the different products: selling dairy products (MILKOIL) increases the probability of adopting a common label, while selling fruits and vegetables sector (FVEG) increases the probability of adopting a brand.

This contrasting result also holds for export markets and marketing channels. If exporting to European markets (EXINEU) increases the adoption of both signals, the co-operatives exporting outside of the European Union borders (EXOUTEU) are less likely to choose a label. In marketing channels, compared to the co-operatives network, transacting with a reduced number of big partners like supermarket and wholesalers increases the probability of adopting a brand. Whereas having different marketing channels (LT50SM, i.e. less than $50 \%$ of turnover with the same marketing channel) increases the probability of adopting a common label.

The bivariate probit estimation leads to a contrasting result: on the one hand, the positive correlation coefficient suggests a complementary effect, on the other hand the drivers of the quality

\footnotetext{
${ }^{15}$ Among the co-operatives, the processors are indeed the smallest (see footnote 1). But the dummy variable control only of the fixed effect. For the slope, we have to consider a probit model counterpart to the Chow test (Wooldridge, 2010). That is, suppose that the constant term and the coefficient of other explanatory variables are the same whether PROC equals 1 or 0 , against the alternative that an altogether different equation applies for the two group of co-operatives, those with $\mathrm{PROC}=1$ and those with $\mathrm{PROC}=0$. The restricted model in this instance would be based on the pooled data set of all 993 observations. The log-likelihood for the pooled model (which has all the explanatory variables without PROC) is -548 . The log-likelihoods for the model based on the 684 observations with $\mathrm{PROC}=1$ and the 304 observations with PROC $=0$ are -405 and -157 , respectively. The log-likelihood for the unrestricted model with separate coefficient vectors is thus the sum, -562. The chi-squared statistic for testing the restrictions of the pooled model is twice the difference, $\operatorname{LR}=2[-548-(-562)]=28$. At the $5 \%$ significance level, the hypothesis that the coefficients of the explanatory variables are the same is rejected.
} 
signals (label and brand) suggest a substitutability effect. The estimation of the bivariate model with correction for endogeneity bias (see model 4) does not significatively changed this result: only the signs of some product variables and the dummy variable for processing co-operatives (PROC) changed for the Label choice ${ }^{16}$. As explained above, this can be due to unobserved heterogeneity that may bias the estimation results. To circumvent the problem, we can use exclusion restriction and test indirectly for complementarity. This can be done by estimating a multinomial logit model for the mutually exclusive signals.

\section{- insert Table 4 -}

\subsection{The multinomial logit}

We go further into the small co-operative choice for a particular quality signal. In order to do so we apply the indirect test for complementarity that we described in the previous section. Under the assumption that co-operatives make the best choice in quality signal we estimate a multinomial logit model for their actual choices (NOSIG, LABEL, BRAND, LABRAND). We estimate the following model of quality signal choice

$$
\operatorname{Pr}(Y=j)=\frac{e^{X_{i} \beta}}{\sum_{i=1}^{4} e^{X_{i} \beta}}
$$

with $j \in\{L A B E L, B R A N D, L A B R A N D, N O S I G\}$ and $X_{i}$ a vector of characteristics of cooperative $i$. Co-operatives choosing no signal (NOSIG) serve as the reference case.

Notice that in contrast to the bivariate model alternatives are exclusive in the multinomial logit, i.e. each co-operative can only belong to one of the four groups. This implies that the multinomial logit model reveals drivers of exclusive combinations of the different quality signals, more particularly the drivers of the mix signal (LABRAND). Indeed, while the bivariate probit restricts the coefficients of the exogenous variables to be the same for all LABEL (BRAND) decisions, the multinomial logit model allows coefficients to vary across exclusive alternatives.

This allows us to apply the indirect test for complementarity. Recall that this test relies on an exclusion restriction that affects the use of one of the quality signals in isolation as well as the combine use of both signals while not the use of the other signal in isolation. To apply the indirect test for complementarity between signals we need some theoretical predictions. The literature on

\footnotetext{
${ }^{16}$ We also made the correction for the endogeneity bias of the variable SUBSID (see the multinomial logit, table 5) and the variable TURN. In a companion paper, we indeed estimate an ordered bivariate probit (Kaminski and Thomas, 2011) where turnover and quality signals are simultaneously chosen. We find a clear and positive effect of the turnover on the probability of choosing a quality signal.
} 
supermarkets (Liesbeth et al., 2004) provides us with a theoretical argument from an instrument variable with a focus on brand. Compared to the other marketing channels, quality signals are widespread and more diverse in supermarkets.

On one hand, suppliers have incentives to develop their own brand strategy to get a larger share of the price premium paid by consumers. Supermarkets may also receive some profit from this strategy since a brand signal is a credible commitment that the suppliers will provide a quality good. This could help to sustain the supermarket reputation as a third party guarantor of quality (Bigaiser 1993, Biglaiser and Friedman 1994). On the other hand, the development of brands when transacting with supermarkets may also have an indirect effect by increasing the return of a labeling strategy. Indeed, the suppliers have some incentives to use other signals to escape from the brands competition with supermarkets that recently developed their own (retailer) brands (Berges et al., 2013).

Another exclusion restriction is used in the brand case. Hayes et al. (2007) show that brand is the more common signal in the fruit and vegetables sector. The fruit and vegetables market is very competitive and thus less likely to the development of labels, with very few co-operatives able to ensure a collective action on common labeling adoption and diffusion. But with the development of the organic label (AB) in the fruit and vegetables short supply chains (Torre and Traversac, 2011), co-operatives that have chosen a brand signal may also add the AB label on products coming from organic farming. In this case, choosing a brand can also have an indirect effect in the probability of adopting a label signal (e.g. organic label, AB).

Two further restrictions are used that center around labels. We expect that the label choice depends on some specific governance of the co-operatives (Sykuta and Cook, 2001). That is, the more a co-operative is associated or member of a union of co-operatives (UNION), the more it will adopt a common label (Fillipi, 2010). This can be explained by the fact that the co-operative does not usually have the full decision rights on its marketing strategies (Hendriksen and Bijman, 2002) and just follows the common labeling strategy of the union. But the larger the total sales of the "small" co-operative, the higher its decision rights and thus its negotiation power inside the union to develop (or maintain) its own signal strategy. For such co-operatives, it can indeed be worthwhile to increase differentiation by using a mixed signal, i.e. adding a private signal on common labeling.

The estimation results of the multinomial logit (without and with endogeneity bias correction; see table 5) show that some of our exclusion restrictions for the indirect test do work. The supermarket variable impacts the choice of brand in isolation as well as the joint use of label and brand (LABRAND), while there is no impact on the choice of label only signal. In contrast if the retailers (RET) and wholesalers (WS) variables significantly affect the probability of the mixed signal (LABRAND), they do not significantly affect stand-alone signals (LABEL and BRAND). Hence, we can conclude that choosing the supermarket as a marketing channel increases the expected marginal returns from brand in the presence of labels (mixed signal).

Similarly, the results also show that making less than $50 \%$ of its turnover with the same marketing channel also increases the marginal gains from brand when labels are chosen. The exclusion 
restrictions on labels, those builds on the governance of the co-operatives, also show that the level of total sales (TURN) and the association/membership to an union are important for the label signal, and that the marginal gains from this signal are higher if brands are in place. This last result is however not robust to endogeneity bias correction since there is no significative impact of the variables TURN and UNION on the mix signal adoption while they have a positive effect on the brand choice. We also find no significative correlation between Union and subsidiary decisions on one hand and the mix signal adoption on the other hand.

However, we find no significant effect for the other exclusion restriction on brand. If selling fruit and vegetables increases the probability of choosing a brand, it has no significant effect on the mixed signal adoption. Therefore, there is no indirect effect of selling fruit and vegetables on the probability of choosing a label. This result is robust to endogeneity treatment.

The indirect test of complementarity using a multinomial logit does therefore not provide a conclusive result. For some exclusion restrictions, the indirect test shows that there is evidence of complementarity but for one another there is no complementary effect.

\section{- insert Table 5 -}

\subsection{The Multinomial Probit}

In contrast to the previous models, where we have only indirect test of the complementary effect, the multinomial probit is able to provide a reliable direct test of complementarity ${ }^{17}$.

As in the multinomial logit model, and in contrast to the bivariate probit, the multinomial probit model is less restrictive on the effects that exogenous control variables can have on the different choices, allowing coefficients to vary across exclusive combinations of quality signals. The difference is that for the mixed signal (LABRAND), the only explanatory variable is the constant, which captures the complementary effect. Like the bivariate probit model, and in contrast to the multinomial logit, it is possible to estimate a coefficient of correlation between the error terms, which captures the unobserved heterogeneity.

Therefore, as discussed in section 3, with a multinomial probit we have a consistent model of complementarity and we can account for the unobserved co-operative heterogeneity. It is indeed possible to separate complementarity between the strategies from the unobserved heterogeneity, since we can estimate both: ( $i$ ) the parameter $\theta$ (the constant term in the regression), which captures complementarity; and (ii) the parameter $\rho$ (the correlation coefficients between the errors),

\footnotetext{
${ }^{17}$ For the previous estimations, we used classic commands under Stata 13. To estimate our specific MNP model, there is no such classic command either under STATA or under other econometric softwares. We developed our own program under $\mathrm{R}$ using the MNP package.
} 
which captures the unobserved heterogeneity between co-operatives. This separation cannot be done with the previous two models, i.e. bivariate and multinomial logit models.

The results of the multinomial probit estimation in table 4 indicate that there is complementarity between quality signals, since the complementarity parameter $(\theta)$, captured by the constant coefficient, is significant for the mixed signal choice (LABRAND). The complementarity here is a substitution effect since the sign of the coefficient is negative (-6.44). This result implies that the positive sign in the coefficient correlation found in the previous bivariate probit regression does not captures a complementarity effect, but only some unobserved heterogeneity between co-operatives that explain the mixed signal choice. Indeed, the coefficient of correlation in the multinomial probit $(\rho=0.63)$ is positive and significant.

This finding on the substitution effect is consistent with the difference in the drivers of standalone signals (LABEL and BRAND). While exporting inside of the EU (EXINEU) increases the probability of adopting a label, exporting out of the European Union (EXOUTEU) reduces this probability. This result is magnified by the regional effect and the origin of the product. Indeed, making less than 50\% total sales in the region (LT50INREG) reduces the probability of choosing a label. In contrast, exporting out of the EU increases the probability of adopting a brand since the positive sign of the coefficient turns to be significant in the multinomial probit, which was not the case in the previous regressions.

This mainly shows that brand signal is made for export outside of the EU while labels are profitable inside of the EU market. This is consistent with the idea that labels, mainly IGs and PDOs, have an access to institutional recognition and protection from the European Union that make them profitable. Outside the borders of the EU markets, this protection is less effective and consequently the trademark system, and thus branding, is more efficient.

\section{- insert Table 6 -}

\section{Conclusion}

Many quality signals, mainly brands and common labels, have been developed to foster the development of food quality in the agro-food markets. Previous research has typically focused on either brand or common label efficiency independently, while in many instances both signals coexist. Agricultural products pairing brand names and certified labels, such as indications of origin, are indeed very common (e.g. Roquefort cheese, Scottish whiskeys and most of the French wines).

The objective of our paper is to take into account this coexistence by empirically analyzing the complementarity and/or substitutability that may exist between labels and brands. To do so, we 
develop a multinomial probit model of complementarity that we test on a database of the quality signaling strategies from 993 small French co-operatives. Our main result shows that there is a clear interaction effect between brand and label signal strategies, but this is more a substitution effect than a complementary one. The positive correlation that can be observed between both signals is only due to the unobserved heterogeneity between co-operatives.

Given the lack of previous empirical work on this topic of coexistence of quality signals, the first results generated by this research provide some interesting suggestions for further theoretical work regarding the complementarity between quality signals. Introducing new questions in the survey, e.g. on contracting and governance mechanisms of the co-operatives, may help to better control for the unobserved heterogeneity. A panel data set on the different surveys on co-operatives signal choices would allow us also to control for unobserved specific effects. 


\section{Appendix: endogeneity problem}

In our estimation, there may be an endogenity bias since a variable like UNION (being a member or associated to an union of cooperative) may impact (negatively) the adoption of a brand signal but also the error term. The obvious solution to the endogeneity problem is to include variables that may control for the quality signalling decision inside the cooperative. But we do not have such information in our database. The instrumental variable approach provides an alternative solution. We introduce new sets of variables which the property that changes in these variables are associated with changes in UNION but do not lead to changes in LABEL. The regression model with the dependent variable $y_{1}$ (LABEL) depends on one endogenous regressor, denoted by $\mathbf{y}_{2}$ and exogenous regressors, denoted by $\mathbf{x}_{1}$ :

$$
y_{1}=\beta_{11} \mathbf{x}_{1}+\beta_{21} \mathbf{y}_{2}+\varepsilon_{1}
$$

where the regression errors $u$ are assumed to be uncorrelated with $\mathbf{x}_{i}$ but are correlated with $\mathbf{y}_{2}$. A consistent estimator can be obtained if we assume that there are instruments $\mathbf{x}_{2}$ correlated with $\mathbf{y}_{2}$ and that satisfy the assumption $E\left(u \mid \mathbf{x}_{2}\right) \mid=0$. That is, $\mathbf{y}_{2}$ must satisfy the first stage equation with only exogenous variables on the right-hand side.

$$
\mathbf{y}_{2}=\alpha_{12} \mathbf{x}_{1}+\alpha_{22} \mathbf{x}_{2}+\varepsilon_{2}
$$

Using the gross correlation between endogenous variable and instruments and between instruments, we select a regional instrument for the endogenous regressor: south region in France (SOUTH) where there is more Union of cooperatives than in other regions in France. We begin with 2SLS IV regression of LABEL on the endogenous regressor UNION, instrumented by these two instruments, and several exogenous regressors (model 2 in table 4). We also consider estimation of an overidentified model with 2SLS estimation and by different variants of GMM. But there is very small variations since the parameter of estimates have changed by less than $10 \%$ between the two methods. To test for endogeneity, we compare if there is a significant difference between OLS and IV estimators, by using the Durbin-Wu-Hausman test with robust variance estimates (Davidson, 2000). The F-stat leads to rejection of the null hypothesis that UNION is exogenous. We conclude that UNION is endogenous.

To account for the binary nature of the endogenous regressor UNION, we can change the first stage equation to be a latent-variable $y_{2}^{*}$ that determines whether $y_{2}=1$ or 0 . That is,

$$
\begin{gathered}
y_{2}^{*}=\alpha_{12} \mathbf{x}_{1}+\alpha_{22} \mathbf{x}_{2}+\varepsilon_{2} \\
y_{2}= \begin{cases}1 & \text { if } y_{2}^{*}>0 \\
0 & \text { otherwise }\end{cases}
\end{gathered}
$$

The errors $\left(\varepsilon_{1}, \varepsilon_{2}\right)$ are assumed to be correlated bivariate normal with $\operatorname{Var}\left(\varepsilon_{1}\right)=\sigma^{2}, \operatorname{Var}\left(\varepsilon_{2}\right)=1$ and $\operatorname{Cov}\left(\varepsilon_{1}, \varepsilon_{2}\right)=\rho \sigma^{2}$. And the binary endogenous regressor $\left(y_{2}\right)$ can be viewed as a treatment 
indicator. If $y_{2}=1$, the cooperative receives treatment, i.e. it has access to UNION membership, and if $y_{2}=0$, it does not receive treatment. We use the treatreg command in Stata to estimate this model (model 3 in table 4 ) with the two instruments. Compared with IV estimation, we have an increase precision of the estimation since the coefficient of UNION has increased from -0.617 to -0.278 and the standard error has fallen greatly from 0.259 to 0.095 . And the Wald test of independence between error terms in the two equations $(\rho=0)$ shows that the exogeneity hypothesis is rejected at the $5 \%$ threshold.

We want to go further and account also for the binary nature of the dependent variable LABEL. Bhattacharya et al. (2006) show that the bivariate probit performs best in generating consistent estimates of the treatment effect (in our case, the effect of union association/membership on the probability of choosing a label). Since it can also be interesting to simultaneously estimate the brand decision as well as the label decision, we estimate we estimate the following trivariate recursive model (see model 4 in table 4 )

$$
\begin{gathered}
\left\{\begin{array}{l}
y_{1}=\beta_{11} y_{2}+\beta_{21} \mathbf{x}_{1}+\varepsilon_{1} \\
y_{3}=\beta_{13} y_{2}+\beta_{23} \mathbf{x}_{1}+\varepsilon_{3} \\
y_{2}=\alpha_{12} \mathbf{x}_{1}+\alpha_{22} \mathbf{x}_{2}+\varepsilon_{2}
\end{array}\right. \\
y_{i}= \begin{cases}1 & \text { if } y_{i}^{*}>0, i=1, \ldots 3 \\
0 & \text { otherwise }\end{cases}
\end{gathered}
$$

where $\varepsilon_{i}$ are error terms distributed as multivariate normal, each with mean of zero, and a variancecovariance matrix $\sum$ where values of 1 on the leading diagonal and correlations $\rho_{j k}=\rho_{k j}$ as of diagonal elements. We estimate this recursive trivariate probit model using the multivariate (mvprobit) command, with robust standard errors, in STATA. The mvprobit command uses the GHK simulation method for maximum likelihood estimation of the multivariate probit regression model. The results of the estimation with a correction of the endogeneity bias for the variable Union show two things. First, its sign nor significativity have changed: it has still a non-significative impact on Label and a positive and significative effect on Brand. Second, if the correlation parameter between Union and Label decisions is not significative, the one between Union and Brand is negative. This may suggest that there are unobserved variables that have a positive impact on Union and a negative impact on brand decision.

To correct for endogeneity bias in the multinomial logit model, we also used the multivariate probit 
approach. Following (11), we estimated a fifth-variate model

$$
\begin{aligned}
\left\{\begin{array}{l}
y_{1}=\beta_{11} \mathbf{x}_{1}+\beta_{21} y_{2}+\beta_{31} y_{3}+\varepsilon_{1} \\
y_{4}=\beta_{14} \mathbf{x}_{1}+\beta_{24} y_{2}+\beta_{34} y_{3}+\varepsilon_{4} \\
y_{5}=\beta_{15} \mathbf{x}_{1}+\beta_{25} y_{2}+\beta_{35} y_{3}+\varepsilon_{5} \\
y_{2}=\alpha_{12} \mathbf{x}_{1}+\alpha_{22} \mathbf{x}_{2}+\varepsilon_{2} \\
y_{3}=\alpha_{13} \mathbf{x}_{1}+\alpha_{23} \mathbf{x}_{2}+\varepsilon_{3}
\end{array}\right. \\
y_{i}= \begin{cases}1 & \text { if } y_{i}^{*}>0, i=1, \ldots 5 \\
0 & \text { otherwise }\end{cases}
\end{aligned}
$$

where $\left(y_{1}, y_{4}, y_{5}\right)$ represent the three decision (observed) variables on quantity signaling (respectively, LABRAND, BRAND, LABEL) and $\left(y_{2}, y_{3}\right)$ the two endogenous variables (respectively, UNION and Subsidiary). 


\section{References}

[1] Akerlof G. (1970). The Market for Lemons: Quality Uncertainty and the Market Mechanism. Quarterly Journal of Economics 84: 488-500.

[2] Anders, Sven and Caswell, Julie A. (2009). The Benefits and Costs of Proliferation of Geographical Labeling for Developing Countries, Estey Centre Journal of International Law and Trade Policy, vol. 10(1).

[3] Arora, A. (1996). Testing for Complementarities in Reduced-Form Regressions. Economic Letters 50: 51- 55 .

[4] Arora, A. and A. Gambardella (1990). Complementarity and external linkages: the strategies of the large firms in biotechnology. Journal of Industrial Economics 38: 361-379.

[5] Athey, S. and S. Stern (1998). An Empirical Framework for Testing Theories about Complementarity in Organizational Design. NBER working paper \#6600.

[6] Aubert, M., and Perrier-Cornet, P. (2009). Is there a future for small farms in developed countries? Evidence from the French case. Agricultural Economics 40: 797-806.

[7] Belderbos R., Carree M., and Lokshin B. (2006). Complementarity in R\&D cooperation strategies. Review of Industrial Organization 28: 401-426.

[8] Berges-Sennou, F., Hassan D. and Monier-Dilhan S. (2013). Are consumers more loyal to National Brands than to private labels. Bulletin of Economic Research 65(1): ps1-s16.

[9] Bhattacharya, J., Goldman, D. and McCaffrey, D. (2006). Estimating probit models with self-selected treatments. Statistics in Medecine 25(3): 389-413.

[10] Biglaiser, G. (1993). Middlemen as experts. RAND Journal of Economics 24: 212-223.

[11] Biglaiser, G. and J. Friedman (1994). Middlemen as guarantors of quality. International Journal of Industrial Organization 12: 509-531.

[12] Boizot-Szantai, C. and Lecocq, S. and Marette, S. (2005). Common Labels and Market Mechanisms. Center for Agricultural and Rural Development (CARD) Publications 05-wp405, Center for Agricultural and Rural Development (CARD) at Iowa State University).

[13] Bonnet, C. and M. Simioni (2001). Assessing Consumer Response to Protected Designation of Origin Labeling: A mixed Multinomial Logit Approach. European Review of Agricultural Economics 28(4): 433-439.

[14] Braham, E. (2003). Translating terroir: the global challenge of French AOC labeling. Journal of Rural Studies 19: 127-138. 
[15] Cassiman, B. and R. Veugelers (2006). In Search of Complementarity in the Innovation Strategy: Internal R\&D, Cooperation in R\&D, and External Technology Acquisition. Management Science 52: 68-82.

[16] Chambolle C., and E. Giraud-Héraud (2005). Certification de la Qualité par une AOC: Un Modèle d'Analyse. Review of International Economics 13: 461- 471.

[17] Chan Choi S. and Coughlan A. (2006). Private label positionning: quality versus feature differentiation from the national brand. Journal of Retailing 82(2): 79-83.

[18] Cook, M. and C. Iliopoulos (2001). Ill-Defined Property Rights in Collective Action: The case of US Agriculture Cooperatives. In Ménard C. (Ed), Institutions, Contracts and Organizations: Perspectives from New Institutional Economics. pp 335-348. London: Edward Elgar.

[19] Cook, M. and M. Sykuta (2001). A New Institutional Economics Approach to Contracts and Cooperatives. American Journal of Agricultural Economics 83(5): 1273-1279.

[20] Costanigro, M., Bond, C.A., and McCluskey, J.J. (2012). Reputation Leaders, Quality Laggards: Incentive Structure in Markets with Both Private and Collective Reputations. Journal of Agricultural Economics 63(2): 245-264.

[21] Crespi, J. and S. Marette (2003). Some Economic implications of Public Labeling. Journal of Food Distribution Research 34(3): 83-94.

[22] Darby, M. and Karni, E. (1973). Free Competition and the Optimal amount of Fraud. Journal of Law and Economics 16(1): 67-88.

[23] Fares, M. (2013). Using a multinomial probit to test for complementarity. Applied Economics Letters 21(3):180-184.

[24] Filippi, M. (2010). Alliance and Partnerships in the development of competences in agricultural co-operatives. Canadian Review of Regional Science 33(1): 115-132 (in french).

[25] Gentzkow, M. (2007). Valuing New Goods in a Model with Complementarity: Online Newspapers. American Economic Review 97: 714-744.

[26] Gergaud, O. and Ginsburgh, V. (2008). Natural endowments, production technologies and the quality of wines in Bordeaux. Does terroir matter? Economic Journal 118(529): F142-157.

[27] Giovannucci, D., T. Joslin, W. Kerr, B. O’Connor, and M. Yeung (2009): Guide to Geographical Indications. Linking Products to their Origins. Geneva: International Trade Centre.

[28] Hayes, D. J., Lence, S. H. and Stoppa, A. (2004). Farmer-owned brands. Agribusiness 20: 269 -285 .

[29] Hendriksen, G. and Bijman J. (2002). Ownership structure in agrifood chains: the marketing co-operative. American Journal of Agricultural Economics 84(1): 104-19. 
[30] Haussman, H. (1996). The Ownership of Entreprise. Cambridge: The Belknap Press of Howard University Press.

[31] Hu, W., Batte, M., Woods, T. and Ernst, S. (2011). Consumer preferences for local production and other value-added label claims for a processed food product. European Review of Agricultural Economics 41(5): 1-22.

[32] Kaminski, J. and A. Thomas (2011). Land Use, Production Growth, and the Institutional Environment of Smallholders: Evidence from Burkinabe Cotton Farmers", Land Economics, 87(1): 161-182.

[33] Keane, M. (1992). A note on identification in the multinomial probit model. Journal of Business and Economic Statisics 10: 193-200.

[34] Klein, B. and Leffler, K. (1981). The Role of Market Forces in Assuring Contractual Performance. Journal of Political Economy 89(4): 615-634.

[35] Landon, S and C. Smith (1997). The Use of quality and Reputation indicators by Consumers: the Case of Bordeaux Wine. Journal of Consumer Policy 20(3): 289-302.

[36] Landon, S and C. Smith (1998). Quality Expectations, Reputation and Price. Southern Economic Journal 64(3): 628-634.

[37] Lence, S., Marette S., Hayes, D. and W. Foster (2007). Collective Marketing Arrangements for Geographically Differentiated Agricultural Products: Welfare Impacts and Policy Implications. American Journal of Agricultural Economics 89: 947-963.

[38] Liesbeth D., T. Reardon and J. Swinnen (2004). The Rapid Rise of Supermarkets in Central and Eastern Europe: Implications for the Agrifood Sector and Rural Development. Development Policy Review 22 (09): 525-556.

[39] Loureiro, M.L. and McCluskey, J.J. (2000). Assessing Consumers Response to Protected Geographical Identification Labeling. Agribusiness 16(3): 309-320.

[40] Marette S., Crespi J.M. (2003). Can Quality Certification Lead to Stable Cartels ? Review of Industrial Organization 23: 43-64.

[41] Marette, S. Clemens, R. and Babcock, B. (2008). The recent international and regulatory decisions about Geographical indications. Agribusiness, 24 (4): 453-472.

[42] Menapace, L., and G. Moschini (2012). Quality Certification by Geographical Indications, Trademarks and Firm Reputation. European Review of Agricultural Economics 39(4): 539566.

[43] Mérel, P. (2009). On the Deadweight Cost of Production Requirements for Geographically Differentiated Agricultural Products. American Journal of agricultural Economics 91: 642655 . 
[44] Milgrom, P. and J. Roberts (1990). The Economics of Modern Manufacturing: Technology, Strategy, and Organization. American Economic Review 80: 511-528.

[45] Miravete, E. and J. Pernias (2010). Testing for Complementarity when Strategies are Dichotomous. Economics Letters 106: 28-31.

[46] Mohnen, P. and Röller L. (2005). Complementarities in innovation policy. European Economic Review 49: 1431-1450.

[47] Shapiro, S (1983). Premium for high quality products as returns of reputation. The Quarterly Journal of Economics 98: 660-679.

[48] Sykuta M., and Cook M. (2001). A New Institutional Economics Approach to Contracts and Cooperatives. American Journal of Agricultural Economics 83 (5): 1273-1279.

[49] Thiedig, F. and Sylvander B. (2000). Welcome to the Club ? An Economical Approach to Geographical Indications in the European Union. Agrarwirtschaft 49(1): 428-437.

[50] Tirole, J. (1996). A theory of Collective Reputations (with Applications to the Persistence of Corruption and to Firm Quality). Review of Economic Studies 63: 1-22.

[51] Torre A., and Traversac JB. (2011): Territorial Governance: Local Development, Rural Areas and Agrofood Systems. Physica-Verlag, Springer.

[52] Topkis, D. (1978). Minimizing a Submodular Function on a Lattice. Operations Research 16(2): 305-321.

[53] United States Patent and Trademark Office (2003). http://www.ustpo.gov.

[54] Vanhonacker, F., Verbeke, W., Guerrero, L., Claret, A., Contel, M., Scalvedi, L., ZakowskaBiemans, S., Gutkowska, K., Sulmont-Rosse, C., Raude, J., Granli, B.S., and Hersleth, M. (2010). How European consumers define the concept of traditional food: evidence from a survey in six countries. Agribusiness 26: 453-476.

[55] Winfree J. and J. McCluskey (2005). Collective Reputation and Quality. American Journal of Agricultural Economics 87: 206-213.

[56] Yue C, Marette S., and Beghin, J. (2006). How to Promote Quality Perception in Wine Markets: Brand Advertising or Geographical Indication? Center for Agricultural and Rural Development (CARD) Publications 06-wp426, Center for Agricultural and Rural Development (CARD) at Iowa State University.

[57] Wooldridge, J. (2010). Econometric Analysis of Cross Section and Panel Data. 2d edition. MIT Press. 
Table 1: Descriptive statistics on Small French Co-operatives

\begin{tabular}{|c|c|c|c|c|c|}
\hline & All & Nosig & label & brand & $\operatorname{mix}$ \\
\hline Nbre observations & 993 & 293 & 475 & 50 & 175 \\
\hline$\%$ Associate/member of an union & $40 \%$ & $30 \%$ & $46 \%$ & $48 \%$ & $40 \%$ \\
\hline$\%$ Own a subsidiary & $14 \%$ & $11 \%$ & $14 \%$ & $14 \%$ & $22 \%$ \\
\hline Wholesaler & $69 \%$ & $51 \%$ & $77 \%$ & $80 \%$ & $77 \%$ \\
\hline \multicolumn{6}{|l|}{ Products } \\
\hline -Beverage & $48 \%$ & $36 \%$ & $44 \%$ & $68 \%$ & $75 \%$ \\
\hline -Crops & $6 \%$ & $15.5 \%$ & $2 \%$ & $2 \%$ & $2.5 \%$ \\
\hline -Fruits and Vegetables & $7.5 \%$ & $8 \%$ & $6.5 \%$ & $12 \%$ & $7.5 \%$ \\
\hline -Milk and oil & $28.5 \%$ & $23 \%$ & $42 \%$ & $8 \%$ & $6 \%$ \\
\hline -Meat & $5 \%$ & $5 \%$ & $4.5 \%$ & $7 \%$ & $6 \%$ \\
\hline -others & $5 \%$ & $13 \%$ & $1 \%$ & $4 \%$ & $2 \%$ \\
\hline Less than $50 \%$ of total sales in the same region & $22 \%$ & $19 \%$ & $16 \%$ & $42 \%$ & $35 \%$ \\
\hline More than $50 \%$ of total sales with the same marketing channel & $86 \%$ & $91.5 \%$ & $85 \%$ & $88.5 \%$ & $79 \%$ \\
\hline - with Cooperative network & $30 \%$ & $32.5 \%$ & $33 \%$ & $26 \%$ & $17 \%$ \\
\hline - with wholesalers & $18 \%$ & $12.5 \%$ & $19 \%$ & $24 \%$ & $24.5 \%$ \\
\hline - with Retailers & $10 \%$ & $15 \%$ & $7 \%$ & $8.5 \%$ & $10 \%$ \\
\hline - with Supermarkets & $5 \%$ & $3 \%$ & $4 \%$ & $16 \%$ & $8.5 \%$ \\
\hline - with Others (hostels, restaurants, ...) & $23 \%$ & $28.5 \%$ & $22 \%$ & $14 \%$ & $19 \%$ \\
\hline Average total sales turnover & 1.99 & 1.86 & 1.94 & 1.90 & 2.35 \\
\hline Average number of members & 98 & 117 & 74 & 141 & 120 \\
\hline Average number of employees & 3.5 & 2.1 & 3.4 & 5.2 & 5.6 \\
\hline \% exporting inside EU borders & $20 \%$ & $8.5 \%$ & $16 \%$ & $26 \%$ & $44 \%$ \\
\hline - Average $\%$ of total sales in export & $12 \%$ & $20.5 \%$ & $11 \%$ & $18 \%$ & $9 \%$ \\
\hline \% exporting outside EU borders & $5 \%$ & $2 \%$ & $3.5 \%$ & $10 \%$ & $12 \%$ \\
\hline - Average $\%$ total sales in export & $10 \%$ & $52 \%$ & $3.6 \%$ & $7.5 \%$ & $4.2 \%$ \\
\hline
\end{tabular}


Table 2: Labels adopted

\begin{tabular}{|c|c|c|c|}
\hline \multicolumn{2}{|c|}{ Label adoption } & \multicolumn{2}{|c|}{ Type of labels } \\
\hline no label & $34 \%$ & & \\
\hline at least one label & $66 \%$ & IGs (AOC, IGP) & $81 \%$ \\
\hline - 1 label & $85 \%$ & $\mathrm{AB}$ & $12 \%$ \\
\hline - 2 labels & $12 \%$ & Label Rouge & $4 \%$ \\
\hline - 3 labels & $2 \%$ & $\mathrm{CCP}$ & $2 \%$ \\
\hline-4 labels & $1 \%$ & Others & $1 \%$ \\
\hline
\end{tabular}


Table 3: Description of variables

\begin{tabular}{|c|c|c|c|c|c|}
\hline Variable & Definition & Mean & S. D. & Min. & Max. \\
\hline \multicolumn{6}{|l|}{ Size and structure } \\
\hline MEM & Number of members & 98.37 & 183.7 & 0.00 & 3200 \\
\hline EMP & Number of employees (from 0 to 10 ) & 3.53 & 3.64 & 0.00 & 10 \\
\hline UNION & $=1$ if Union association or membership & 0.40 & 0.49 & 0.00 & 1.00 \\
\hline SUBSID & $=1$ if coop has a subsidiary & 0.14 & 0.34 & 0.00 & 1.00 \\
\hline TURN & Sales turnover (millions $€$ ) & 1.99 & 2.88 & 0.00 & 31.3 \\
\hline \multicolumn{6}{|l|}{ Activity } \\
\hline $\mathrm{PC}$ & $=1$ if the coop is a processor; $=0$ if its is a wholesaler & 0.69 & 0.46 & 0.00 & 1.00 \\
\hline \multicolumn{6}{|l|}{ Products } \\
\hline MILKOIL & $=1$ if coop produces milk \& oil (reference) & 0.28 & 0.45 & 0.00 & 1.00 \\
\hline $\mathrm{BEV}$ & $=1$ if coop produces beverages & 0.48 & 0.50 & 0.00 & 1.00 \\
\hline CER & $=1$ if coop produces cereals & 0.06 & 0.23 & 0.00 & 1.00 \\
\hline FVEG & $=1$ if coop produces fruits $\&$ vegetables & 0.07 & 0.26 & 0.00 & 1.00 \\
\hline MEAT & $=1$ if coop produces meat & 0.05 & 0.22 & 0.00 & 1.00 \\
\hline OTHERS & $=1$ if coop produces other products & 0.05 & 0.22 & 0.00 & 1.00 \\
\hline \multicolumn{6}{|l|}{ Export Markets } \\
\hline EXINEU & $\%$ of turnover by exports within EU & 0.35 & 0.89 & 0.47 & 4.60 \\
\hline EXOUTEU & $\%$ of turnover by exports outside EU & 0.06 & 0.39 & 0.39 & 4.60 \\
\hline \multicolumn{6}{|l|}{ Local Market } \\
\hline LT50INREG & $=1$ if less than $50 \%$ of total sales is made in the same region & 0.21 & 0.41 & 0.00 & 1.00 \\
\hline \multicolumn{6}{|l|}{ Marketing Channels } \\
\hline LT50SM & $=1$ if $\leq 50 \%$ of total sales with the same marketing channel & 0.14 & 0.35 & 0.00 & 1.00 \\
\hline - Co-operative network & $=1$ if dealing with a coop network (ref) & 0.29 & 0.45 & 0.00 & 1.00 \\
\hline - SUPER & $=1$ if dealing with supermarket & 0.05 & 0.21 & 0.00 & 1.00 \\
\hline - RET & $=1$ if dealing with a retailer & 0.10 & 0.29 & 0.00 & 1.00 \\
\hline$-W S$ & $=1$ if dealing with a wholesaler & 0.18 & 0.18 & 0.00 & 1.00 \\
\hline - OTHERS_HOT & $=1$ if dealing with hotels $\&$ restaurants & 0.23 & 0.42 & 0.00 & 1.00 \\
\hline
\end{tabular}




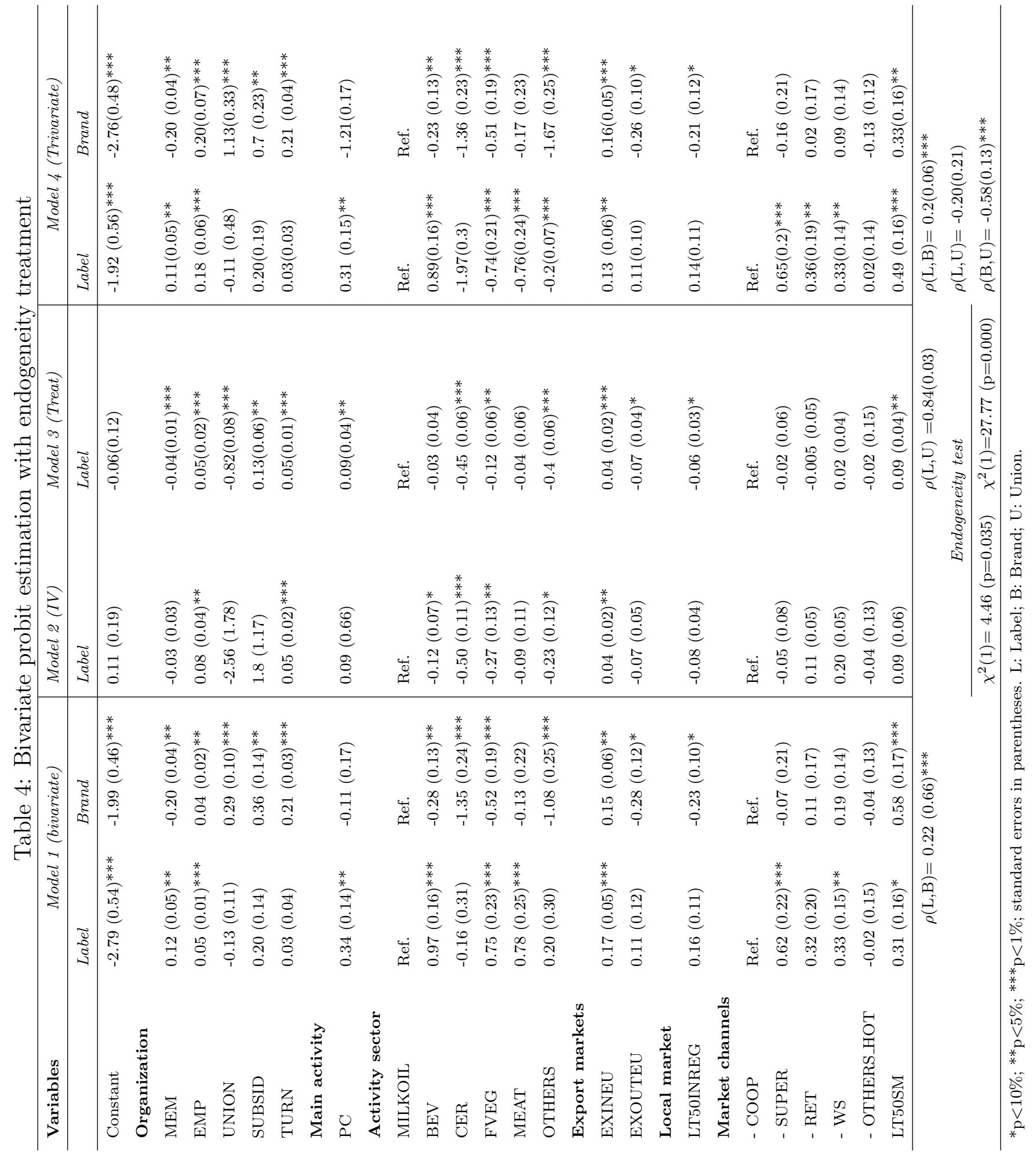




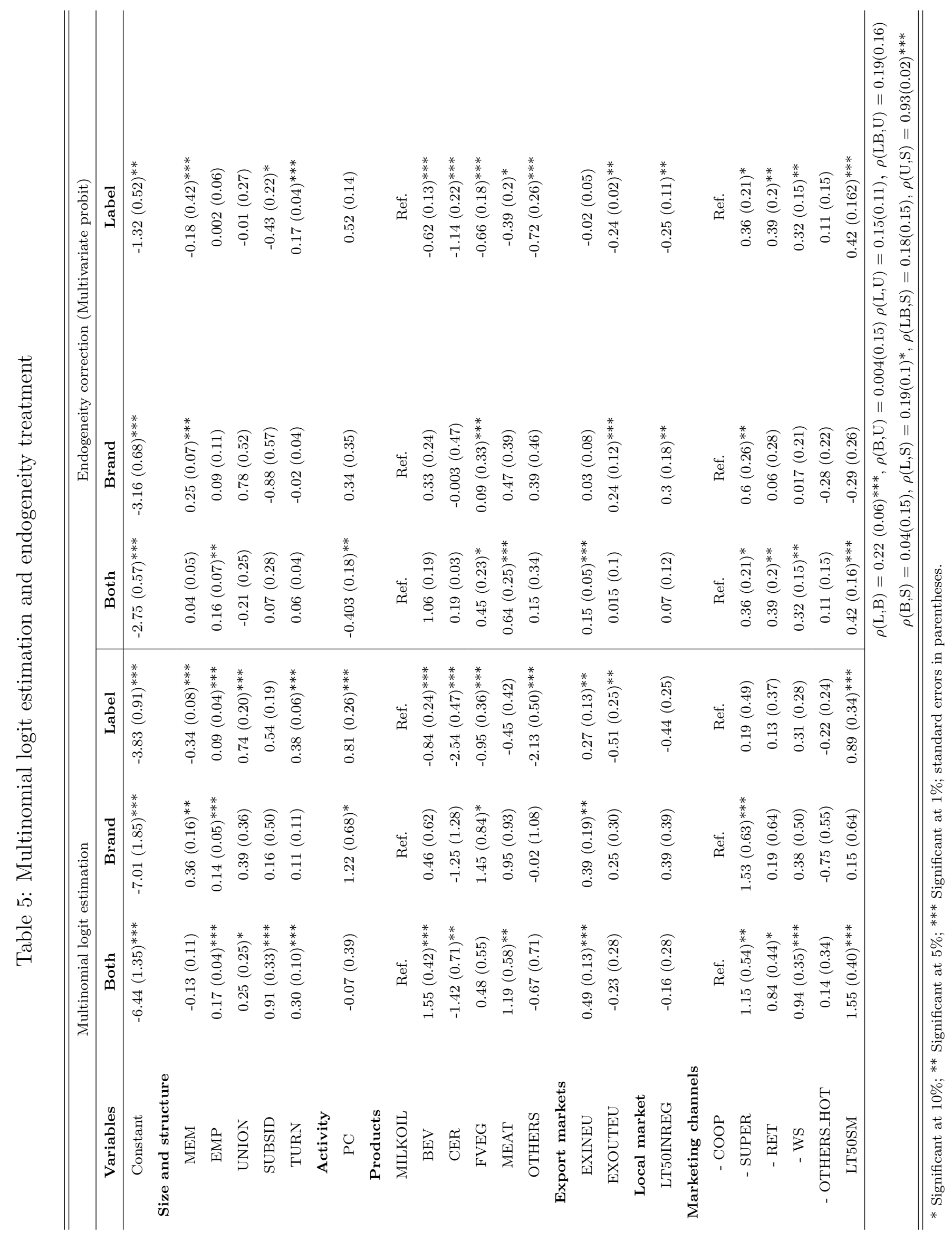




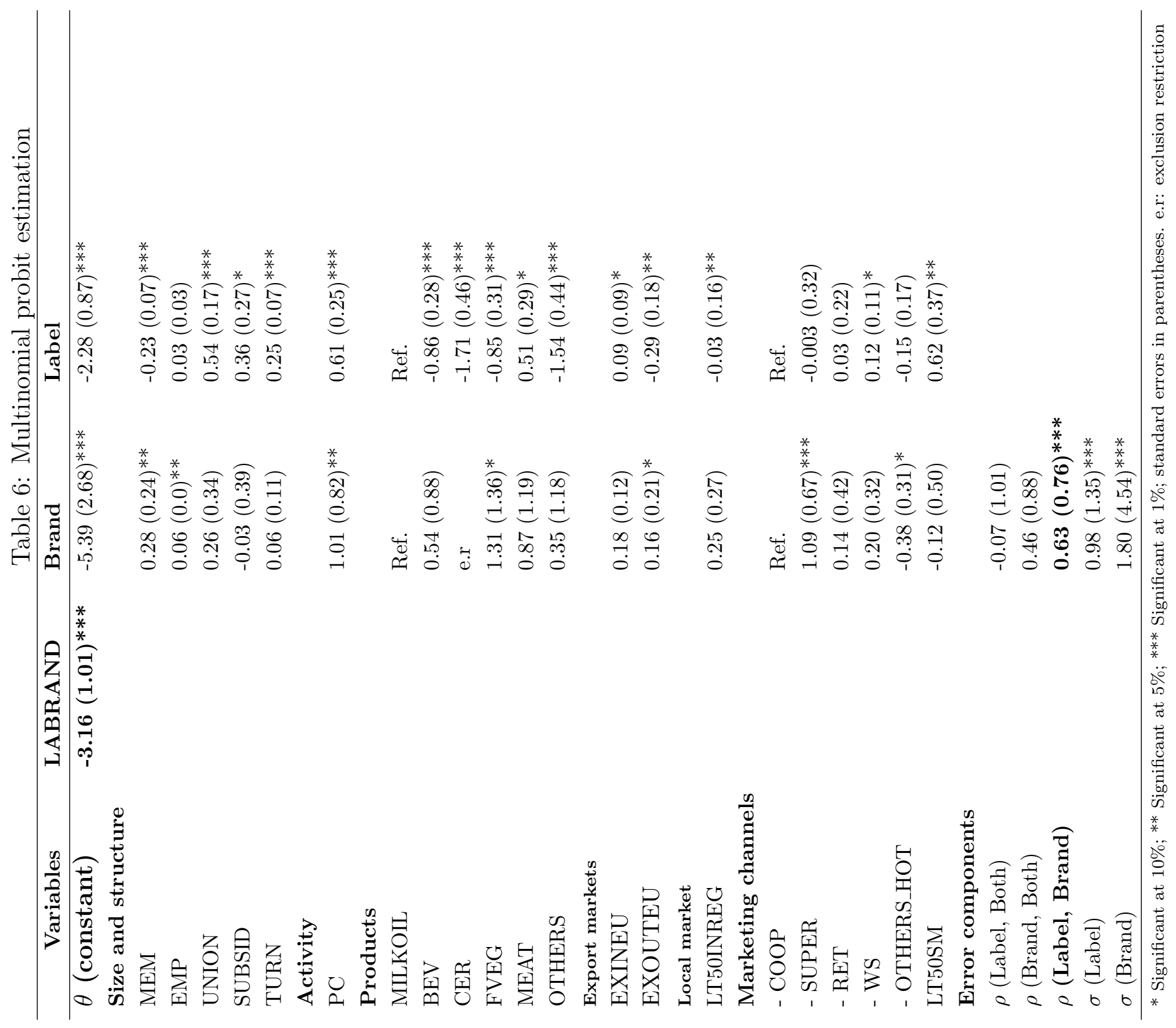

